\title{
VS38: a new monoclonal antibody for detecting plasma cell differentiation in routine sections
}

\author{
H Turley, M Jones, W Erber, K Mayne, M de Waele, K Gatter
}

\begin{abstract}
Aims-To characterise a new mouse monoclonal antibody, VS38, which recognises an intracytoplasmic antigen of 64 kilodaltons present in normal and neoplastic plasma cells; and to establish its value as a diagnostic reagent for routine pathological practice.

Methods-A range of normal and neoplastic tissue sections, both frozen and routinely fixed, were immunostained, using the microwave method of antigen retrieval for routinely fixed specimens. The antibody was also tested on blood and bone marrow specimens and a range of human cell lines. The molecular weight of the antigen recognised by the antibody was obtained by western blot analysis. FACS analysis was used to demonstrate the cellular location of the antigen and its presence on tonsil cell suspensions and myeloma cases.

Results-VS38 recognised normal and neoplastic plasma cells in all of the tissues, including all routinely fixed plasma cell neoplasms tested. The antibody also weakly stained epithelial elements within the tissue but was absent from haemopoietic cells of other lineages.

Conclusion-Antibody VS38 is of potential value in identifying myeloma or plasmacytoma in bone marrow or other tissues. It differentiates lymphoplasmacytoid lymphoma from lymphocytic and follicular lymphoma. It also subdivides large cell lymphomas into two groups which may be a more reliable method of separating these tumours than morphology alone.
\end{abstract}

(F Clin Pathol 1994;47:418-422)

The terminal stage of B cell differentiation is the plasma cell for which no unique antigens have yet been described. Apart from their morphology, plasma cells are usually distinguished from other B cells by their lack of surface HLA class I and class II antigens, surface immunoglobulin, $\mathrm{Fc}$ and $\mathrm{C} 3$ receptors, and the presence of intracytoplasmic immunoglobulin. ${ }^{1}$ Most antibodies which stain plasma cells label other B cells as well as cells of other lineages. ${ }^{2-6}$ Most do not work on routinely fixed material, thus further limiting their usefulness to pathologists.

We describe the characterisation of a mouse monoclonal antibody, VS38, that is reactive with an antigen expressed strongly on normal and neoplastic plasma cells but is absent from haemopoietic cells of other lineages. This antigen is also expressed to some extent in both normal and neoplastic epithelial cells. VS38 was tested on a wide range of normal and neoplastic tissues including solid tumours as well as blood and bone marrow specimens, with the aim of establishing its value as a diagnostic reagent for pathological practice.

\section{Methods}

PRODUCTION OF ANTIBODY VS 38

The source of antigen was a membrane preparation of MCF-7 AdR cells. About $4 \times 10^{5}$ cells were injected intraperitoneally into a Balb/c mouse, together with Freund's complete adjuvant. Eleven days later, the mouse was given a booster injection of $1.6 \times 10^{6}$ cells, with non-complete adjuvant. The booster was repeated again seven days later. Three days after the last injection the mouse was killed and the spleen removed. Cell suspensions were prepared from the spleen and were fused with cells from the myeloma cell line NS1s, using polyethylene glycol to induce cell fusion, as described by Mason and colleagues. $^{7}$

BIOCHEMICAL ANALYSIS OF THE VS38 EPITOPE Cell cultures were washed twice with phosphate buffered saline (PBS) and then harvested with $0.25 \%$ trypsin and $0.02 \%$ EDTA. The cell suspension was washed in culture medium and centrifuged for five minutes at $1000 \mathrm{rpm}$ and $4{ }^{\circ} \mathrm{C}$. The cells were washed twice in PBS and centrifuged for a final spin at $2000 \mathrm{rpm}$ for 10 minutes at $4^{\circ} \mathrm{C}$. The cell pellet was solubilised with an equal volume of $1 \%(\mathrm{v} / \mathrm{v})$ Triton X-100 (Sigma) in $10 \mathrm{mM}$ TRIS-HCL (pH 8) for 20 minutes on ice. This was then spun at $2000 \mathrm{rpm}$ for $15 \mathrm{~min}$ utes at $4^{\circ} \mathrm{C}$ and the supernatant fluid collected. This was either used immediately for analysis by polyacrylamide gel electrophoresis (PAGE), or stored as a membrane extract at $-70^{\circ} \mathrm{C}$

\section{SDS-PAGE}

Sodium dodecyl sulphate (SDS) polyacrylamide gel electrophoresis was performed on the extract, according to the method of Laemmli. ${ }^{8}$ Samples were suspended in buffer containing DL-dithiothreitol (Sigma) and boiled for two minutes, allowed to cool, and 
loaded on to a gel (5.5\% stacking gel, $6.5 \%$ running gel). Molecular weight markers (Sigma UK) were run at the same time.

Proteins were transferred electrophoretically using a Transblot (Biorad UK) apparatus to nitrocellulose membranes ${ }^{9}$ and the protein detected by applying the antibody, followed by a rabbit-anti-mouse peroxidase conjugate (Dako UK) and visualised using diaminobenzidine with metal ion enhancement. ${ }^{10}$

\section{TISSUES}

A representative range of normal and neoplastic tissues, including bone marrow biopsy specimens, was obtained from the Histopathology Department at the John Radcliffe Hospital. Tissues were immediately snap frozen in liquid nitrogen and stored at $-70^{\circ} \mathrm{C}$. Cryostat sections $(5-8 \mu \mathrm{m})$ were then cut and collected on to glass multiwell slides and dried overnight at room temperature. The slides were then fixed in acetone at room temperature. The sections were either stained immediately or stored wrapped in aluminium foil at $-20^{\circ} \mathrm{C}$ until staining. Formalin fixed, paraffin wax embedded sections were cut at approximately $5 \mu \mathrm{m}$ and floated on to silane coated glass slides. These were dewaxed, rehydrated, and microwaved in a 700 Watt microwave for 8 minutes in $0.01 \mathrm{M}$ sodium citrate, then into buffer before staining as normal. ${ }^{11}$

\section{CELL LINES}

The following cell lines were obtained from

\section{A B C} the Sir William Dunn School of Pathology, Oxford: K562 (erythroleukaemia); HeLa (cervical epithelial carcinoma); U937 (malignant histiocytosis); HL60 (promyelocytic leukaemia); RVH421 (melanoma); A431 (vulval carcinoma); Daudi and Raji (Burkitt's lymphoma); Nalm-1 (pre-B cell leukaemia); and Jurkat ( $\mathrm{T}$ cell lymphoma). The cell lines L428 (Hodgkin's disease) and Thiel (plasma cell) were obtained from Dr V Diehl; SUDHL-1 ( $T$ cell leukaemia) from Dr ML Cleary; Karpas 299 ( $\mathrm{T}$ cell lymphoma with a 2:5 translocation) and Karpas $M$ (plasma cell) from Dr A Karpas; and HT29 (colon carcinoma), MCF 7 ADR (breast carcinoma) from the Imperial Cancer Research Fund, London. The plasma cell lines L363, JJN3, Karpas 707, OPM-1, and EJM were obtained from Professor K Nilsson, University of Uppsala, Sweden. LB 84-4 (plasma cell), ARH 77 (plasma cell), and 8226 R10 (plasma cell) were from Professor Brian GM Durie. All cell lines were cultured in RPMI containing $10 \%$ fetal calf serum (Gibco Biocult Ltd) at $37^{\circ} \mathrm{C}$. Cytocentrifuge preparations were made using a Shandon cytocentrifuge. These were allowed to air dry for at least two hours, then fixed for 10 minutes in acetone.

\section{BLOOD AND BONE MARROW SAMPLES}

Samples were obtained from the Haematology Department of the John Radcliffe Hospital and cytospins were prepared and allowed to dry at room temperature overnight. The slides were then fixed in acetone/methanol ( 1 in 1 ) for 60 seconds at room temperature, placed into TBS $(0.5 \mathrm{M}$ TRIS, $\mathrm{pH} 7 \cdot 6$, diluted 1 in 10 in $0 \cdot 15 \mathrm{M}$ saline) and either stained using the alkaline phosphatase-antialkaline phosphatase (APAAP) technique, or stored wrapped in aluminium foil at $-20^{\circ} \mathrm{C}$ until required. They were then allowed to reach room temperature before fixation, as described.

IMMUNOCYTOCHEMICAL STAINING

The APAAP staining technique was performed, as described before. ${ }^{12}$ The enzyme reaction was developed using napthol-ASMX-phosphate and fast red (TR-Salt, Sigma Chemical Co) as substrate. For immunoperoxidase labelling tissue sections were incubated first with the monoclonal antibody for 30 minutes, then with peroxidase conjugated rabbit-anti-mouse (Dakopatts), and finally with peroxidase conjugated swine-anti-rabbit immunoglobulin. ${ }^{13}$ The peroxidase reaction was developed using diaminobenzidine (Sigma Chemical Co). The slides were then washed and mounted in aqueous mountant (Apathy's; BDH Poole, Dorset).

\section{FACS ANALYSIS}

White cells and mononuclear cells were isolated from peripheral blood and bone marrow aspirates by red cell lysis using ammonium chloride $^{14}$ or density centrifugation on Lymphoprep (Nygaard, Oslo). The peripheral blood cells were permeabilised using buffered formol acetone (BFA), as described by Slaper-Cortenbach et al. ${ }^{15}$ After washing in phosphate buffered saline (PBS) containing $0.1 \%$ bovine serum albumin (BSA), permeabilised cells were incubated for 30 minutes at $4^{\circ} \mathrm{C}$ with the antibodies. Cells were then washed and incubated for 30 minutes with fluorescein isothiocyanate (FITC) conjugated rabbit-anti-mouse $F\left(a^{\prime}\right) 2$ immunoglobulin (Dakopatts a/s). After a final wash the cells were fixed in $1.5 \%$ formaldehyde in washing buffer and analysed in a FACScan flow cytometer (Becton Dickinson) using Consort 30 and Paint-a-Gate software.

\section{Results}

BIOCHEMICAL ANALYSIS OF EPITOPE

A strong band of molecular weight 64 kilodaltons (reduced) was detected by VS38 from extracts of the cell lines Thiel (plasma cell derived), MCF-7, and MCF-7 ADR (breast carcinoma derived) (fig 1). Occasionally a higher molecular weight band of 73 kilodaltons was detected in the MCF-7 ADR cell line (fig 1). No bands could be detected without reducing conditions.

\section{NORMAL TISSUE REACTIVITY}

Frozen/fresh material

VS38 was tested on a wide range of normal tissues (table 1). The most striking result is the intense cytoplasmic labelling of all plasma cells (fig 2). All other lymphoid cells were unlabelled. Weak staining of epithelium was detectable in most tissues, and in some cases 
Table 1

\begin{tabular}{ll}
\hline Normal tissue staining of routinely fixed specimens \\
\hline Tonsil & Weak epithelium \\
Gut & APUD cells \\
Pancreas & Exocrine positive, endocrine negative \\
Lung & Plasma cells \\
Brain & Neurones, glial cells \\
Heart & No staining \\
Cerebellum & Purkinje cells \\
Adrenal & Glomerulosa cells \\
Kidney & Distal tubules, Bowman's capsule \\
Spleen & No staining \\
\hline
\end{tabular}

APUD: Amine precursor uptake decarboxylase.

weak endothelial staining was also present. Peripheral blood lymphocytes were unstained, although some weak staining of monocytes and neutrophils could occasionally be detected.

\section{Fixed material}

Without microwave pre-treatment no reactivity could be detected on routinely fixed sections whether or not enzyme predigestion was utilised. However, after heating in a sodium citrate solution intense cytoplasmic labelling of plasma cells was seen (fig 2). Other lymphoid cells were negative. Of note was the fact that the epithelial cell labelling seen in most tissues on frozen section examination was considerably reduced or absent in these specimens (fig 2). We also observed strongly labelled spindle cells within the stroma of

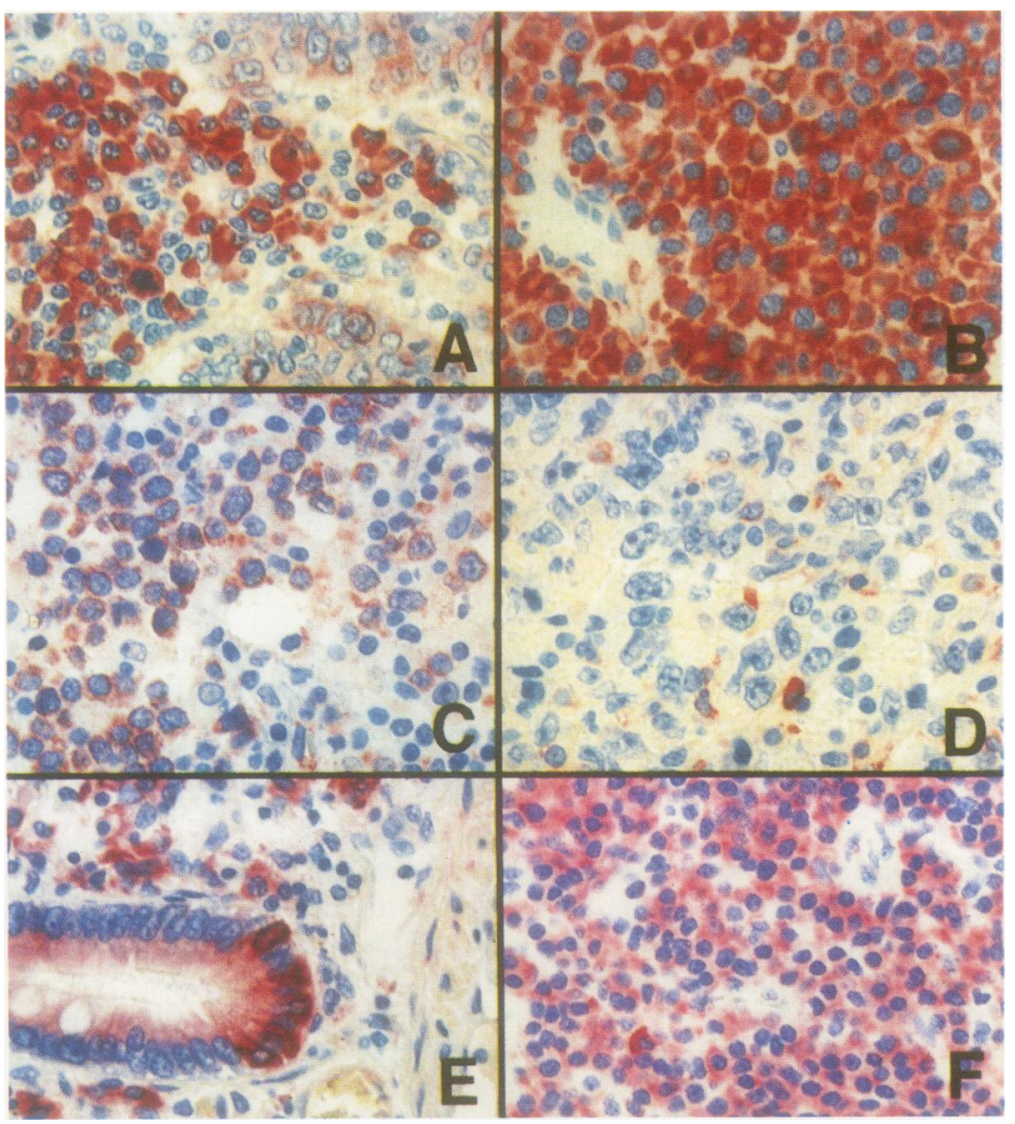

Figure 2 (A) Strongly labelled plasma cells surrounded by a weakly positive squamous cell carcinoma of the lung. (B) Positive labelling of myeloma cells. (C) Large cell B lymphoma showing positive staining of the malignant cells contrasted with (D) a large cell B lymphoma in which the lymphoma cells are unstained (note a fert scattered positive plasma cells). (E) Small intestine showing strong positivity of APUD cells in the glandular crypts. (F) Low grade lymphoplasmacytoid lymphoma uniformly stained though not as intensely as the myeloma (B). some tissues but were unable to identify these cells.

\section{FACS}

Analysis of the tonsil cell suspensions, myeloma cases, and the plasma cell lines with and without permeabilisation showed that the antigen is intracytoplasmic being undetectable without prior permeabilisation (fig 3 ).

REACTIVITY OF VS38 WITH HUMAN CELL LINES The antibody reacted with all the plasma cell lines tested. This reactivity was strong and present on all of the cells in the sample. All of the lymphocytic lines were unreactive with VS38 apart from Nalm-1 which showed a weak positivity. Of the myeloid lines tested, only U937 was reactive. The carcinoma lines were also weakly positive in keeping with the tissue staining. The single melanoma cell line examined RVH421 was also positively labelled.

\section{REACTIVITY WITH LYMPHOMAS AND} LEUKAEMIAS

The results of staining lymphoma specimens with VS38 are summarised in table 2. All specimens of myeloma and plasmacytoma were strongly labelled (fig 2) as were the lymphoplasmacytoid elements in all of the lymphoplasmacytic lymphomas. Only in frozen sections was there staining of follicular lymphoma and common lymphocytic leukaemia (CLL). In these cases staining was generally focal and weak (fig 2). There was no staining of $T$ cell lymphomas but 10 of the fixed large $B$ cell lymphomas were positive, albeit much more weakly than the myelomas (fig 2 ).

\section{Discussion}

No plasma cell specific antigens have been described to date, with all of the previously reported antibodies also labelling other cell types, most notably other B cells. . $^{3-16-18}$ Two antibodies well known to haematologists, PCA1 and PCA2, ${ }^{16}$ were reported as being expressed on plasma cells but were also present on granulocytes and monocytes. Other examples more familiar to histopathologists might include antibodies against EMA (epithelial membrane antigen) and CD30 (notably antibody Ber-H2). ${ }^{19-21}$ Most importantly none of these antibodies has been shown to detect all (or virtually all) plasma cells in formalin fixed material, the main interest of the current study to practising histopathologists. The only antibody other

Table 2 VS38 immunostaining on lymphoma

\begin{tabular}{lll}
\hline Diagnosis & Frozen & $\begin{array}{l}\text { Paraffin } \\
\text { wax }\end{array}$ \\
\hline CLL & $7 \star / 13$ & $0 / 12$ \\
Centroblastic centrocytic lymphoma & $2 / 7$ & $0 / 6$ \\
Hairy cell leukaemia & $0 / 8$ & $0 / 4$ \\
Lymphoplasmacytoid lymphoma & $2 / 2$ & $7 / 7$ \\
B cell large cell non-Hodgkin's lymphoma & $0 / 8$ & $12 / 38$ \\
T cell non-Hodgkin's lymphoma & NT & $0 / 9$ \\
Myeloma & $42 / 42$ & $7 / 7$ \\
Plasmacytoma & NT & $4 / 4$ \\
\hline
\end{tabular}

Key: NT = not tested. ${ }^{\star}$ weak/focal staining. 
UNPERMEABILISED

A

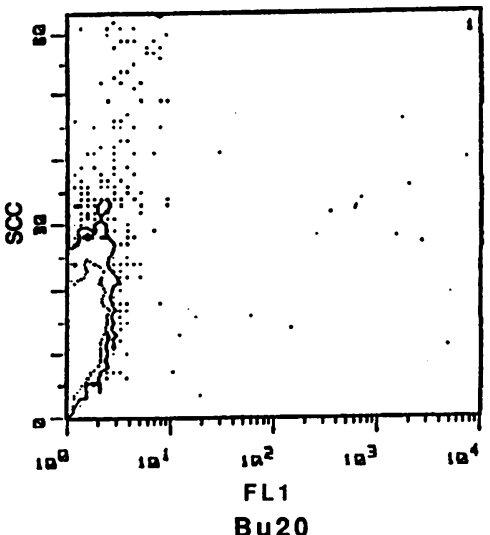

C

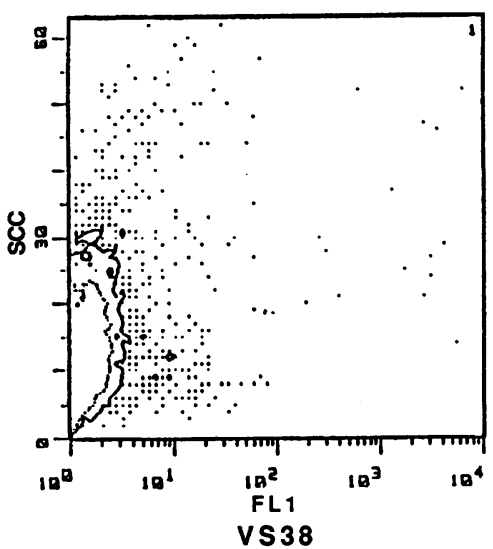

PERMEABILISED B

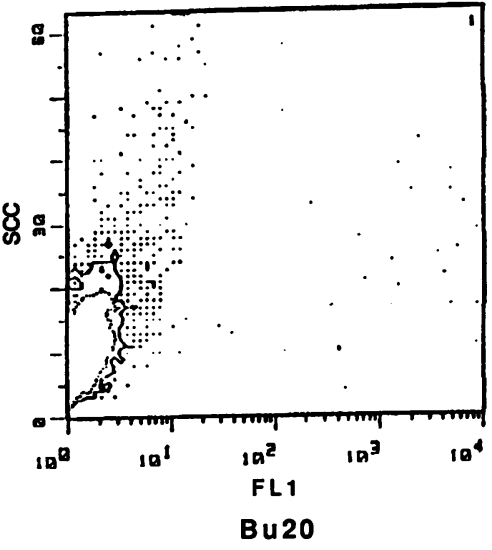

D

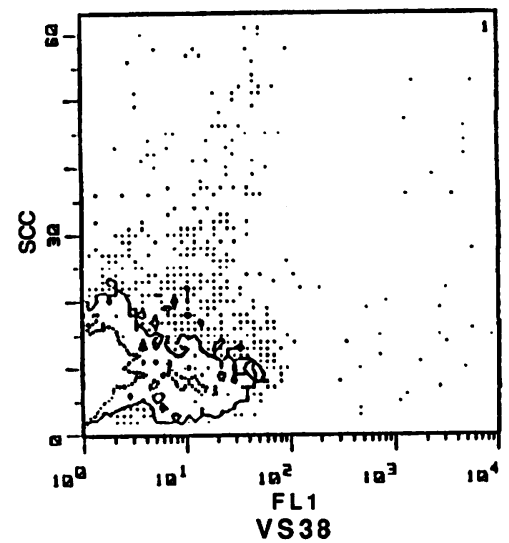

Figure 3 FACS analysis of a bone marrow sample from a case of multiple myeloma. Antibody VS38 shows no surface staining of the neoplastic cells (C). However, following $B F A$ permeabilisation (D), the myeloma cells are labelled by antibody VS38. (A) and (B) show the absence of labelling obtained with antibody Bu20 (negative control) before and after permeabilisation. (SSC = side scatter)

than anti-Ig antibodies described to date, which stains neoplastic plasma cells in fixed sections, is antibody MM4..$^{5} \mathrm{~A}$ drawback of this antibody is that only a subset of the myeloma cells is positive, and this could be a potential problem in small or lightly infiltrated biopsy specimens.

In the current study we have shown that the recently produced antibody VS38 is of potential value in clinical practice. It can be helpful in identifying myeloma or plasmacytoma in bone marrow and other tissues. It also helps to distinguish cases of lymphoplasmacytoid lymphoma from lymphocytic and follicular lymphoma. The only other lymphomas showing positivity were about one third of the cases of large cell non-Hodgkin's lymphoma. It might be predicted that these would be the immunoblastic rather than the centroblastic or other cell types. However, this is a notoriously difficult area of morphology with very little consensus among pathologists about their identification.

Indeed, a study undertaken by Warnke et al ${ }^{22}$ more than 10 years ago showed that even expert haematopathologists disagreed on the subdivision of large cell lymphomas. They not only disagreed with each other but also with themselves when they re-examined individual cases. This difficulty is reflected in the Kiel classification which makes substantial efforts to define reliably the distinction between immunoblastic and centroblastic lymphoma. In early studies this group believed that immunoblastic was the commonest large cell non-Hodgkin's lymphoma. This is what the general reader will glean from many textbooks-for example, The Oxford Textbook of Pathology ${ }^{23}$ and the first edition of Lymph Node Biopsy Interpretation by Stansfeld. ${ }^{24}$ In the second edition of Stansfeld's book the revised Kiel classification is used and the following explanation is given for centroblastic now being the most common large cell nonHodgkin's lymphoma.

"Formerly believed to be the commonest type of high grade large cell lymphoma it is now clear that ML-IB-B (immunoblastic) is less common than centroblastic lymphoma. This reversal is largely due to the inclusion in the ML centroblastic-polymorphic category of tumour as containing a large number of immunoblasts when it can be shown that the tumour is basically of follicular centre cell origin." 25 This undoubtedly reflects difficulty in making the diagnostic subdivision rather than any change in the incidence of the different subtypes of disease.

Separation of these large cell cases on the grounds of reproducible immunostaining, such as that achieved by VS38, may well be a better way of subdividing large cell lymphomas than by morphological examination alone. It is to be hoped that lymphoma groups will incorporate such findings into their study of non-Hodgkin's lymphomas so that in time a consensus might arise as to whether or not it is useful to subdivide large cell lymphomas and if so on what grounds.

This work was supported in part by the Imperial Cancer Research Fund and the Leukaemia Research Fund.

1 Harris NL. Lymphomas. In: Colvin RB, Bhan AK, McCluskey RT, eds. Diagnostic immunopathology. New Mork: Raven Press, 1988:271-300.

2 Delmastro-Galfrè P, Calabi F, Arno J, Karpas A, Hayhoe FGJ. Monoclonal antibodies specific for human myeloma/plasma cells. In: McMichael AJ, ed. Leucocyte typing III. Oxford: Oxford University Press, 1987: 510-11.

3 Nathan PD, Walker L, Hardie D, et al. An antigenic study of human plasma cells in normal tissue and in myeloma: identification of a novel plasma cell associated antigen. Clin Exp Immunol 1986;65:112-9.

4 Tazzari PL, Gobbi M, Dinota A, et al. Normal and neoplastic plasma cell membrane phenotype: studies with plastic plasma cell membrane phenotype: studies with new monoclon.

5 Tong AW, Lee JC, Stone MJ. Characterization of a monoclonal antibody having selective reactivity with norma and neoplastic plasma cells. Blood 1987;69:238-45.

6 Uckun FM. Regulation of human B-cell ontogeny. Blood 1990;76:1908-23.

7 Mason DY, Cordell JL, Pulford KAF. Production of monoclonal antibodies for immunocytochemical use. In: Bullock GR, Petrusz $P$, eds. Techniques in immunocytochemistry. Vol 2. New York: Academic Press, 1983:175.

8 Laemmli UK. Cleavage of structural proteins during the assembly of the head of bacteriphage T4. Nature 1970;227:680-5.

9 Towbin H, Staehlin T, Gordon J. Electrophoretic transfer of proteins from polyacrylamide gels to nitrocellulose of proteins from polyacrylamide gels to nitrocell
sheets. Proc Natl Acad Sci USA 1979;76:4350-4.

10 Harlow E, Lane D. Antibodies. A laboratory manual. Cold Spring Harbor: Cold Spring Harbor Laboratory, 1988.

11 Cattoretti G, Becker MH, Key G, et al. Monoclonal anti- 
bodies against recombinant parts of the $\mathrm{Ki}-67$ antigen (MIB 1 and MIB 3) detect proliferating cells in microwave-processed formalin-fixed paraffin sections f Pathol 1992;168:357-63.

12 Cordell JL, Falini B, Erber WN, et al. Immunoenzymatic labelling of monoclonal antibodies using immun complexes of alkaline phosphatase and monoclonal antialkaline phosphatase (APAAP complexes). $\mathcal{f}$ Histochem Cytochem 1984;32:219-29.

13 Mason DY, Abdulaziz Z, Falini B, Stein H. Single and double immunoenzymatic techniques for labelling tiss double im 1984;420:1127-33.

14 Carter N. Introduction to the principles of flow cytometry. In: Omerod MG, ed. Flow cytometry $A$ practical approach. Oxford: Oxford University Press, 1989:1-28.

15 Slaper-Cortenbach ICM Admiry IG, Kerr JM Slaper-Cortenbach ICM, Admiraal LG, Kerr JM,
Leeuwen EF, von dem Borne A, Tetteroo PAT. Flow cytometric detection of terminal deoxynucleotidyl transferase and other intracellular antigens in combination with membrane antigens in acute lymphatic leukaemia. Blood 1988;72:1639.

16 Anderson KC, Park EK, Bates MP, et al. Antigens on human plasma cells identified by monoclonal antibodies. IImmunol 1983;130:1132-8.

17 Linden MD, Fishleder AJ, Tubbs RR, Park H. Immunophenotypic spectrum of plasma cell leukemia. Cancer 1989;63:859-62.

18 San MJ, Gonzalez M, Gascon A, et al. Immunophenotypic heterogeneity of multiple myeloma: influence on the biology and clinical course of the disease. CastellanoLeones (Spain) Cooperative Group for the Study of Monoclonal Gammopathies. $\mathrm{Br} \mathcal{F}$ Haematol 1991;77: 185-90.

19 Cordell J, Richardson TC, Pulford KA, et al. Production of monoclonal antibodies against human epithelial membrane antigen for use in diagnostic immunocytochemistry. $\mathrm{Br} \mathcal{F}$ Cancer 1985;52:347-54

20 Schwarting R, Gerdes J, Durkop H, Falini B, Pileri S, Stein H. BER-H2: a new anti-Ki-1 (CD30) monoclonal antibody directed at a formol-resistant epitope. Blood 1989;74:1678-89.

21 Heyderman E, Strudley I, Powell G, Richardson TC, Cordell $\mathrm{L}$, Mason DY. A new monoclonal antibody to epithelial membrane antigen (EMA)-E29. A comparison opithelial membrane antigen (EMA)-E29. A comparison of its immunocytochemical reactivity with polyclonal anti-EMA antibodies and with another monoc

22 Warnke RA, Strauchen JA, Burke JS, Hoppe RT Campbell BA, Dorfman RF. Morphologic types of diffuse large cell lymphoma. Cancer 1982;50:690-5.

23 Isaacson PG. The non-Hodgkin's lymphomas. In: McGee JO, Isaacson PG, Wright NA, eds Oxford textbook of pathology. Oxford: Oxford University Press, 1992: 1775-87.

24 Stansfeld AG. Lymph node biopsy interpretation. Edinburgh Churchill Livingstone, 1985.

25 Stansfeld AG, d'Ardenne AJ, eds. Lymph node biopsy Stansfeld AG, d'Ardenne AJ, eds. Lymph node biopsy
interpretation. Second edn. Edinburgh: Churchill Livingstone, 1992. 